\title{
Sağlık Harcamaları ve Sağlık Göstergeleri Açısından Şanhay İşbirliği Örgüttï Üye Ülkeleri ile Türkiye'nin Karşılaştırılması
}

\author{
Comparison of Shanghai Cooperation Organization Member States and Turkey in terms of The Health \\ Expenditures and Health Indicators
}

\section{Oğuz IŞIK}

Doç. Dr., Hacettepe Üniversitesi ,

IIBF, Sağllk Yönetimi Bölümü,

oguzisik@hacettepe.edu.tr

https://orcid.org/0000-0001-7368-7024

\section{Sevilay KARAMAN}

Arş. Gör., Hacettepe Üniversitesi,

İBF, Sağllk Yönetimi Bölümü,

sevilorak@gmail.com

https://orcid.org/0000-0003-4367-9466
Makale Başvuru Tarihi: 30.07.2019

Makale Kabul Tarihi: 13.09.2019

Makale Türü: Araştırma Makalesi

\section{ÖZET}

$\begin{aligned} & \text { Anahtar } \\ & \text { Kelimeler: }\end{aligned}$
ŞïÖ,
Sağlık
Göstergeleri,
Sağlık
Harcamaları,

Harcamalarl,

Keywords:

$S C O$,

Health Indicators,

Health Expenditure,
Bu çalışmanın amacı; Türkiye için Avrupa Birliği üyelik sürecindeki gelişmelerden dolayı son yıllarda sıklıkla gündeme gelen ve bir alternatif olarak görülen Şanhay İşbirliği Örgütü (ŞIÖ) üye ülkeleri ile Türkiye’nin sağlık harcamaları ve sağlık göstergelerinin karşılaştırılmasıdır. Bu kapsamda ülkelerin demografik, makro ekonomik, sağlık harcamaları ve temel sağlık göstergeleri ile ilgili göstergeler Dünya Bankasi Veri Tabanı'ndan 2000-2005-2010-2015 ve 2017/2018 yllarl kapsayacak şekilde inceleme kapsamına alınmıştır. Sonuç olarak Türkiye kişi başına sağlık harcaması, toplam sağlık harcamalarında kamu payı açısından değerlendirildiğine Şİ̈’ye üye ülkelerin tamamından daha yüksek; cepten yapılan să̆lık harcamalarının toplam să̆lık harcamaları içerisindeki payı açısından ise daha düşük değerler almıştır. Temel sağlık göstergeleri açısından karşılaştırıldığında; doğumda beklenen yaşam süresi kadın ve erkekler için ayrı ayrı değerlendirildiğinde; Türkiye; ŞİÖ ülkeleri içinde Çin'den sonra en yüksek değere; bebek ölüm hızları açısından karşılaştırıldığında ise Rusya, Çin ve Kazakistan'dan sonra en düşük değerlere sahiptir.

\section{ABSTRACT}

The aim of this study is to compare health spending and health indicator of Turkey with the ones of the member states of the Shanghai Cooperation Organization, which often seen as an alternative agenda due to developments in the European Union membership process of Turkey in recent years. In this context, indicators related to demographic, macroeconomic, health expenditures and basic health indicators of the countries were retrieved from the World Bank Database covering the years 2000-2005-2010-2015 and 2017/2018. As a result, health spending per capita in Turkey was higher than the one of all member countries of the SCO in comparison with the public share of total health spending and, lower in comparison with the share of out-of-pocket health expenditures in total health expenditures. When compared in terms of basic health indicators and life expectancy at birth of women and men is evaluated separately, Turkey has the highest value after China in the SCO countries, additionally, she has the lowest values after Russia, China, and Kazakhstan in the countries in terms of infant mortality rates. 


\section{GIRISS}

Dünyada ilk kez 19. yüzyılın ikinci yarısında ortaya çıkan bölgeselleşme hareketleri, daha sonraki dönemlerde dalgalı bir seyir izleyerek 1980'lerin sonundan itibaren hızlı bir artış dönemine girmiştir. Bölgesel örgütlerin ve iş birliklerinin kurulmasının temel nedenleri politik teşvikler olsa da kuruluş sonrasında ekonomik faktörler belirleyici olmuş ve bölgesel ve bölge dışı ticareti geliştirme hedefi daha belirgin hale gelmiştir. Özellikle politik nedenlerle kurulan Avrupa Birliği'nin öncülüğünü yaptığı bu süreç bugün devam etmekte ve birçok gelişmiş ve gelişmekte olan ülke bu sürece aktif olarak katılmaktadır. Bu işbirlikçi hareketlerden biri; Orta Asya bölgesinde kurulan ve Avrupa Birliği üyelik sürecindeki gelişmelerden dolayı Türkiye için bir alternatif olarak değerlendirilen Şanhay İşbirliği Örgütü’dür (ŞiÖ).

ŞiÖ Sovyetler Birliğinin dağılmasından sonra bölgedeki sınır anlaşmazlıklarını çözmek ve sınır güvenliğini sağlamak amacıyla Çin, Rusya, Kazakistan, Kırgızistan ve Tacikistan arasında Şanhay Beşlisi (Shanghai Five) adı ile 1996'da kurulmuş, 2001'de Özbekistan'ında katılımı ile Şanhay İşbirliği Örgütü (Sanghay Cooperation Organization) adını almıştır. Türkmenistan dışındaki Orta Asya bölgesini kapsayan ŞiÖ’ye, 2017 yılında Güney Asya'nın iki büyük ülkesi Pakistan ve Hindistan da tam teşekküllü üye devlet statüsü ile dahil olmuştur. Sekiz üye ülkenin dışında Afganistan, Moğolistan, İran ve Belarus gözlemci ülke; Türkiye, Azerbaycan, Sri Lanka, Ermenistan, Kamboçya ve Nepal ise diyalog ortağı ülke statüsü ile ŞïÖ’de yer almaktadır.

ŞïÖnün temel amac1; üye ülkeler arasında karş1lıklı güven, iyi komşuluk ve dostluk ilişkilerinin güçlendirilmesi, bölgesel barış, güvenlik ve istikrarın korunması için ortak çaba sarfedilmesi, terörizm, köktencilik, ayrılıkçılık, örgütlü suçlar ve yasadışı göçle ortak mücadele edilmesi, ayrıca siyaset, ekonomi, bilim ve teknoloji, kültür ve eğitim, enerji, çevre konularında işbirliğinin geliştirilmesi olarak ifade edilmektedir. Bunlara ek olarak, örgütün amacının ABD öncülüğündeki batı bloğuna karşı ayrı bir blok haline geldiği görülmektedir (Eren, 2017:77).

2016 yılında, Şï̈, ABD ve Avrupa Birliği'nden sonra toplam 12.712,5 milyar dolarlık GSYİH (Hindistan ve Pakistan hariç) ile üçüncü sırada yer almaktadır. 2017'de Hindistan ve Pakistan dahil edildiğinde, ŞïÖ 15.252,9 milyar dolar GSYH'ya ulaşmaktadır. Bu durumda ŞïÖ toplam ekonomik çıktısı ve nüfusu ile sırasıyla dünyanının \%20 ve \%40-44'ünü temsil eder hale gelen, küresel en büyük ve en kapsamlı bölgesel örgüt haline gelmektedir. ŞïÖ’nün kuruluş amacı ilk yıllarda sınır güvenliği olmuş olsa da ekonomik ilişkiler ve dış ticaret verileri örgütün temel ilkelerinden olan bölgesel bütünleşme kaidesinin ekonomik anlamda da sağlanmaya çalışıldığının göstergesidir (Yener, 2013:78; Güpgüpoğlu, 2019:45). Üye ülkeler arasındaki dış ticaret hacmi; ŞiÖ kurulmadan önceki 1994-1996 yıllarında 6 milyar dolar civarlarındayken, 2016 yılında bu oran 210 milyar dolara kadar yükselmiştir. Ek olarak örgütün Interbank, Şanghay Kalkınma Fonu ve Şanghay İş Kurulu gibi ek yapılar üretmesi, Merkezi Asya Ortak Pazarı gibi hedeflerinin bulunması örgütü gelecekte ekonomi ve ticaret alanında daha stratejik bir konuma yükselteceği düşünülmektedir (Akçadağ, 2016:1).

Son yıllarda yapılan ŞiÖ zirvelerinde sağlıkla ilgili konularda vurgular yapılmakta, ekonomik işbirliklerinin sağlık alanına da taşınması ile ilgili çalışmalar planlanmaktadır. Bu doğrultuda 2019'da Bıshkek'te yapılan zirvede farklı alanlarda işbirliğini geliştirmek için "Sağllk; Ekonomi; Alternatif Enerji; Edebiyat ve Kültürr; Terörsüz Toplum ve Insani" işbirliği konularını kapsayan ve kısaca "HEALTH" ismini verdikleri bir vizyon konusunda çalışmalar planlanmaktadır (SCO Summit, 2019:1).

\section{2. ŞANHAY İŞBIRLIĞI ÖRGÜTÜ VE TÜRKIYE}

2008 Duşanbe Zirvesi'nde, örgüt'le irtibat kurmak isteyen ve gözlemci konumunda olmayan üçüncü ülke ve uluslararası kuruluşlarla ilişkilerin kurumsal bir çerçeveye oturtulması amacıyla, kurumsal bağın derecesi bakımından "gözlemci ülke" statüsünün altında, "misafir katılımcılar" statüsünün ise üzerinde olan "ŞïÖ Diyalog Ortaklığı Statüsü” adı altında yeni bir mekanizma ihdas edilmiştir. Diyalog Ortaklığı statüsü, gözlemci statüsüne sahip olmayan üçüncü ülkelerin Örgüt'le belirli alanlarda sınırlı işbirliği yapmalarına olanak sağlamaktadır. Türkiye 6-7 Haziran 2012 tarihlerinde Pekin'de düzenlenen ŞïÖ Devlet Başkanları Zirvesi'nde oybirliğiyle Diyalog Ortaklığı'na kabul edilmiştir. 26.04.2013 tarihinde imzalanan "Türkiye Cumhuriyeti'ne Şanhay İşbirliğgi Örgütünün Diyalog Ortağı Statüsü Tanınmasına İlişkin Muhtıra" 01.05.2017 tarih ve 2017/10196 sayılı Bakanlar Kurulu Kararı ile onaylanmış ve 24.05.2017 tarih ve 30075 sayılı Resmi Gazete'de yayımlanmıştır. Söz konusu belge, Diyalog Ortağı Türkiye ile Şiö arasında, başta bölgesel güvenlik, terörle mücadele, uyuşturucu kaçakçılığı ve organize suçların önlenmesi ile ekonomik ve kültürel alanlar olmak üzere çeşitli konularda işbirliğinin geliştirmesini öngörmektedir. Diyalog ortağı statüsü tanımı ŞīÖ Şartnamesi'nin 
14.maddesinde verilmekte; bu statüye sahip ülke veya uluslararası kuruluşların örgütün faaliyetinde karar alma mekanizmalarından uzak olduğu ve yetkisinin sınırlı olduğu belirtilmektedir. Buna rağmen; diyalog ortağı, örgütün faaliyeti için teklif sunabilmekte ve diğer devletlerle örgüt kapsamında işbirliği yapabilmektedir. Diyalog ortağı statüsünde olmasına rağmen, zamanla Türkiye'nin örgüt dâhilinde etkisi artmaya başlamış; ve 2017 yılında Şanghay Enerji Kulübü'nde dönem başkanı olmuştur. ŞïÖ üyesi olmayan bir ülkenin ilk kez bu görevi üstlenmesi açısından önemlidir (T.C. Dışişleri Bakanlığı, 2019:1).

Türkiye'nin olası ŞïÖ üyeliği; Türkiye’ye, Türki Cumhuriyetlerle ekonomik sosyal ve kültürel yakınlaşmaya katk1 sağlaması, petrol ve doğalgaz kaynaklarının dünyaya açılmasında önemli bir enerji koridoru olacak olması, sanayisinde ağılıklı olarak kullandığı doğalgaza erişimde daha avantajı konumda olacak olması, Çin ve Hindistan düşünüldüğünde hem nüfus hem de artan gelir gücü ile büyük bir pazarla yakından ilişkiye geçecek olması açısından bir çok avantajı beraberinde getirecektir (Çoğal, 2011:1).

2005 yılından başlayıp günümüze kadar devam eden tam üyelik müzakereleri sonucunda; ulaştı̆̆ ekonomik büyüklüğe ve üzerine düşen yükümlülükleri yerine getirmesine rağmen Avrupa Birliği’ne (AB) tam üyeliği sağlanamayan Türkiye'nin; ana politik amaçları arasında $\mathrm{AB}$ üyeliğinin yanı sıra yeni işbirlikleri arayışlarına girdiği görülmektedir (Pantucci ve Petersen, 2013:1; Coşkun, 2012:1; Yener, 2013:85). Bu arayışların sonucu olarak üretim faktörlerinin ve buna bağlı olarak finansal piyasaların batıdan doğuya yöneldiği bir süreçte Türkiye, Batı ortaklıklarından uzaklaşarak giderek Rusya ve Çin'le daha yakın ilişkiler kurmaya başlamış ve Asya'daki firsatları değerlendirmeye çalışmaktadır. Yapılan çalışmalarda Türkiye'nin işbirliğini geliştirmesi için önerilen örgütler içerisinde ŞiÖ, İslam İşbirliği Teşkilatı'ndan sonra ilk sırada gelmektedir (Aydın vd, 2018:20). Yapılan başka bir çalışmada ise; AB'nin alternatifi olarak görülen ilk sırada ŞïÖ gelmekte onu sırasıyla Kuzey Amerika (NAFTA), Güney Amerika (Mercosur vb) ve İslam Konferansı Örgütü izlemektedir (Kartal ve Sofyalığlu, 2011:26). Örgütün iki itici gücü olan Rusya ve Çin ile G-20 platformunda yapılan yakın çalışmalar ve ekonomik ilişkiler; diğer üye ülkelerden Kazakistan, Kırgızistan, Özbekistan ve Tacikistan ile olan tarihsel ve kültürel bağlar ŞīÖ ile ilişkilerde önemli gelişmeler olmasını sağlamaktadır (Yener, 2013:85).

Şi̇Ö ile igili yapılan çalışmalar (Kozma, 2019; Sagbansua ve Can, 2011; Eroğlu vd., 2016) incelendiğinde genellikle ithalat, ihracat, enerji ve sınır güvenliği ile ilgili konularda odaklanıldığı görülmekteyken son yıllarda yapılan Şiö zirvelerinde belirlenen hedefler doğrultusunda sağlık alanında da işbirliğine gidilmesi gerektiğinin ifade edildiği dikkat çekmektedir. Hem Türkiye'nin üyelik için görüşmelerini sürdürdügü hem de sağlık alanında da işbirliklerinin hedeflendiği bu süreçte ŞïÖ ülkeleri ile Türkiye'nin sağlık harcamaları ve sağlık göstergelerinin karşılaştırılması önem arzetmektedir.

Ayrıca ilgili literatür incelendiğinde çalışmaların daha çok gelişmiş ülke örnekleri üzerine olduğu dahası Türkiye'nin içinde olduğu karşılaştırmalı örneklerin ise genellikle $\mathrm{AB}$ ve $\mathrm{OECD}$ ülkeleri ile yapılan çalışmalardan oluştuğu anlaşılmaktadır. Bu çalışma ise bunlardan farklı olarak, literatürde sıklıkla kullanılan sağlık ve demografik göstergeler yardımıyla Tükriye ile ŞiÖ ülkeleri (Çin, Hindistan, Kırgızistan, Kazakistan, Pakistan, Rusya Federasyonu, Tacikistan, Özbekistan) arasında bir karşılaştırmayla durum tespiti yapmayı amaçlamaktadır.

\section{SAĞLIK HARCAMALARI VE SAĞLIK GÖSTERGELERİ AÇISINDAN ŞANHAY İ̧̧BIRLIĞİ ÖRGÜTÜ ÜYE ÜLKELER İLE TÜRKIYYE KARŞILAŞTIRMASI}

\subsection{Araştırmanın Amacı}

Ülkelerin sosyo-ekonomik açıdan kalkınmışlık düzeylerinin en önemli göstergelerinden birisi de sağlık hizmetlerinin düzeyidir. Sağlık hizmetlerinin istenen düzeye getirilmesi için bu alana aktarılacak kaynakların yeterli olması ve bu kaynakların etkin kullanımı şüphesiz ki önem arzetmektedir. Bu çalışma ile Şanhay İ̉birliği Örgütü'ne katılmak istenen Türkiye ile üye ülkelerin sağlık harcamaları ve göstergelerinin karşılaştırılması amaçlanmaktadır. 


\subsection{Araştırmanın Tasarımı}

Araştırma kapsamında yer alan ülke karşılaştırmalarında; nüfus ve demografik veriler, makro ekonomik göstergeler, sağlık harcamaları ve sağlık göstergeleri kullanılmıştır. Bu kapsamda ülkeleri nüfus ve demografik bilgiler açısından karşılaştırmak için; toplam nüfus, kadın ve erkek nüfus oranı ve $0-14$ yaş arası nüfusun ve 65 yaş üstü nüfusun toplamının 15-64 yaş arası nüfus sayısına oranlanması ile bulunan bağımlı nüfus oranı inceleme kapsamına alınmıştır. Ülkeleri makro-ekonomik göstergeler açısından karşılaştırmak için GSYH ve kişi başına düşen GSYH değerleri; sağlık harcamaları açısından karşılaştırmak için ise; toplam sağl1k harcamalarının GSYH içindeki payı, kişi başı sağlık harcaması, toplam sağlık harcamalarında kamu sağlık harcamalarının payı (\%) ve cepten yapılan sağlık harcamalarının toplam sağlık harcamaları içindeki payı (\%) verileri kullanılmıştır. Son olarak; ülkelerin temel sağlık göstergelerini karşılaştırmak için, doğumda beklenen yaşam süresi (DBYS), kadınlarda DBYS, erkeklerde DBYS, bebek ölüm hızı, neonatal ölüm hızı ve beş yaş altı ölüm hızı değerleri incelenmiştir.

Araştırmanın evrenini ŞiÖ’ye üye olan ülkeler (Çin, Rusya, Kazakistan, Kırgızistan, Tacikistan, Özbekistan, Pakistan ve Hindistan) ve Türkiye oluşturmaktadır. Bu kapsamda karşılaştırılacak göstergeler de kullanılacak veriler, Dünya Bankası Veri Tabanı'ndan sağlanmıştır. Elde edilen veriler 2000-2005-2010-2015 yılları ile verilerin en güncel yıl olmaları açısından 2017-2018 yıllarından seçilmiştir.

\subsection{Araştırmadan Elde Edilen Sonuçlar}

Sağlık harcamaları artan, gelişmiş ülkelere bakıldığında, sağlık harcamalarındaki artışa genelde yaşlı nüfusun neden olduğu ve nüfus yoğunluğundan ziyade o toplumdaki nüfusun niteliğinden kaynaklandığı görülmektedir (Mendelson ve Schwartz, 1993:123). Hindistan ve Pakistan'ın da üye olması ile birlikte ŞïÖ, dünya nüfusunun \%43-44'ünü temsil etmektedir. Tablo 1'de ŞïÖ'ye üye ülkelerin nüfus ve demografik göstergeleri ile ilgili bilgiler verilmektedir. Yıllar itibariyle bakıldığında tüm ülkelerde nüfus artışı görülmektedir. Toplam nüfus açısından incelendiğinde; Çin ve Hindistan bir milyarın üzerinde nüfusları ile diğer ülkelere kıyasla en yüksek değere sahiptir ve bu ülkeleri 140 milyonun üzerinde nüfus ile Rusya ve Pakistan izlemektedir. Nüfus açısından en düşük değere sahip ülke ise Kırgızistan'dır. ŞiöÖ ülkeleri ile karşılaştırıldığında Türkiye nüfus açısından Çin, Hindistan, Rusya ve Pakistan'dan az; Özbekistan, Kazakistan, Tacikistan, Kırgızistan'dan ise daha fazla nüfusa sahiptir.

Nüfusun cinsiyete göre dağılımı incelendiğinde; Çin, Hindistan, Pakistan ve Tacikistan'da erkek, diğer ülkelerde ise Türkiye'de olduğu gibi kadın nüfusun fazla olduğu görülmektedir. Emeklilik ve sağlı bakım sistemlerindeki devamlılığın sağlanmasında önemli olan bağımlı nüfus oranı açısından incelendiğinde; 20002018 yılları arasında Rusya dışındaki ülkelerde bağımlı nüfus oranının azaldığ görülmektedir. 2018 yılı itibariyle bağımlı nüfus oranı en yüksek ülkenin \%64,4 oranla Pakistan; en düşük ülke ise \%40,5 ile Çin'dir. Türkiye'de bağımlı nüfus oranının yıllar itibariyle azalış gösterdiği ve 2018 yılında $\% 49,1$ olduğu görülmektedir (Tablo 1). 
Tablo 1. Nüfus ve Demografik Bilgiler

\begin{tabular}{|c|c|c|c|c|c|c|}
\hline Gösterge & Ülke & 2000 & 2005 & 2010 & 2015 & 2018 \\
\hline \multirow{9}{*}{$\sum_{\text {壳 }}^{\mathscr{L}}$} & Çin & 1.262 .645 .000 & 1.303 .720 .000 & 1.337 .705 .000 & 1.371 .220 .000 & 1.392 .730 .000 \\
\hline & Hindistan & 1.056 .575 .549 & 1.147 .609 .927 & 1.234 .281 .170 & 1.310 .152 .403 & 1.352 .617 .328 \\
\hline & Kazakistan & 14.883 .626 & 15.147 .029 & 16.321 .872 & 17.542 .806 & 18.276 .499 \\
\hline & Kirgızistan & 4.898 .400 & 5.162 .600 & 5.447 .900 & 5.956 .900 & 6.315 .800 \\
\hline & Pakistan & 142.343 .578 & 160.304 .008 & 179.424 .641 & 199.426 .964 & 212.215.030 \\
\hline & Rusya Federasyonu & 146.596 .557 & 143.518 .523 & 142.849 .449 & 144.096 .870 & 144.478 .050 \\
\hline & Tacikistan & 6.216 .341 & 6.789 .321 & 7.527.394 & 8.454 .028 & 9.100 .837 \\
\hline & Özbekistan & 24.650 .400 & 26.167 .000 & 28.562 .400 & 31.298 .900 & 32.955 .400 \\
\hline & Türkiye & 63.240 .194 & 67.903 .469 & 72.326 .988 & 78.529 .409 & 82.319 .724 \\
\hline \multirow{9}{*}{ 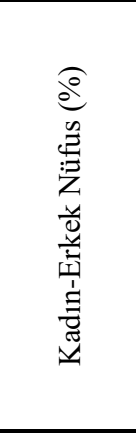 } & Çin & $48,6-51,4$ & $48,6-51,4$ & $48,5-51,5$ & $48,5-51,5$ & $48,5-51,5$ \\
\hline & Hindistan & $48,2-51,8$ & $48,2-51,8$ & $48,1-51,9$ & $48,2-51,8$ & $48,2-51,8$ \\
\hline & Kazakistan & $51,9-48,1$ & $51,8-48,2$ & $51,7-48,3$ & $51,6-48,4$ & $51,6-48,4$ \\
\hline & Kırgızistan & $50,6-49,4$ & $50,4-49,6$ & $50,6-49,4$ & $50,4-49,6$ & $50,4-49,6$ \\
\hline & Pakistan & $48,4-51,6$ & $48,5-51,5$ & $48,6-51,4$ & $48,6-51,4$ & $48,6-51,4$ \\
\hline & Rusya Federasyonu & $53,2-46,8$ & $53,5-46,5$ & $53,6-46,4$ & $53,5-46,5$ & $53,5-46,5$ \\
\hline & Tacikistan & $49,9-50,1$ & $49,7-50,3$ & $49,6-50,4$ & $49,7-50,3$ & $49,8-50,2$ \\
\hline & Özbekistan & $50,3-49,7$ & $50,3-49,7$ & $50,3-49,7$ & $50,2-49,8$ & $50,1-49,9$ \\
\hline & Türkiye & $50,8-49,2$ & $50,8-49,2$ & $50,8-49,2$ & $50,8-49,2$ & $50,7-49,3$ \\
\hline \multirow{9}{*}{ 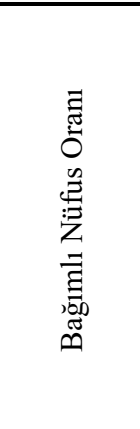 } & Çin & 46,1 & 38,1 & 35,6 & 37,7 & 40,5 \\
\hline & Hindistan & 64,3 & 60,1 & 56,3 & 52,2 & 50,5 \\
\hline & Kazakistan & 52,4 & 47,4 & 44,6 & 50,4 & 55,1 \\
\hline & Kırgızistan & 67,9 & 57,7 & 52,5 & 54,7 & 58,1 \\
\hline & Pakistan & 82,4 & 73,6 & 68,4 & 65,3 & 64,4 \\
\hline & Rusya Federasyonu & 44,3 & 40,8 & 38,8 & 43,5 & 48 \\
\hline & Tacikistan & 85,6 & 72,3 & 64,4 & 62,5 & 63,7 \\
\hline & Özbekistan & 72,1 & 59,8 & 50,7 & 47,7 & 48,5 \\
\hline & Türkiye & 58 & 54,5 & 51,8 & 50,1 & 49,1 \\
\hline
\end{tabular}

Kaynak: Yazarlar tarafından Dünya Bankası veri tabanından elde edilen bilgilere göre hazırlanmıştır.

Tablo 2'de ŞïÖ'ye üye ülkelerin makroekonomik göstergeleri incelendiğinde, ülkelerin GSYH ve Kişi Başına GSYH'nın yıllar itibariyle artış gösterdiği görülmektedir. Buna göre; GSYH açısından en yüksek değere sahip ülkenin Çin, en düşük değere sahip ülkenin ise Tacikistan olduğu görülmektedir. Türkiye GSYH açısından ŞiÖ’ye üye ülkelerle karşılaştırıldığında; Çin, Hindistan ve Rusya'dan düşük; diğer ülkelerden ise yüksek değere sahiptir. Kişi Başına GSYH açısından en yüksek değere sahip ülkenin Kazakistan; en düşük değere sahip ülkenin ise Tacikistan olduğu görülmektedir. Türkiye'nin ise ŞiỔye üye tüm ülkelerden daha yüksek kişi başına GSYH değerine sahip olduğu görülmektedir. 
Tablo 2. Ülkelerin Makroekonomik Göstergeleri

\begin{tabular}{|c|c|c|c|c|c|c|}
\hline Gösterge & Ülke & 2000 & 2005 & 2010 & 2015 & 2018 \\
\hline \multirow{10}{*}{ 莺 } & Çin & 3.707 & 6.624 & 12.446 & 19.821 & 25.362 \\
\hline & Hindistan & 2.279 & 3.488 & 5.382 & 8.036 & 10.498 \\
\hline & Kazakistan & 118 & 216 & 321 & 441 & 509 \\
\hline & Kırgizistan & 8 & 10 & 15 & 21 & 24 \\
\hline & Pakistan & 385 & 550 & 716 & 950 & 1.176 \\
\hline & Rusya Federasyonu & 1.001 & 1.697 & 2.927 & 3.523 & 3.986 \\
\hline & Tacikistan & 6 & 10 & 16 & 24 & 31 \\
\hline & Özbekistan & 49 & 72 & 119 & 188 & 231 \\
\hline & ŞİÖ Ortalama & 968 & 1.438 & 2.641 & 4.003 & 5.227 \\
\hline & Türkiye & 606 & 807 & 1.260 & 2.012 & 2.372 \\
\hline \multirow{10}{*}{ 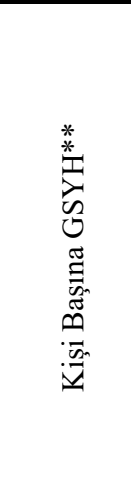 } & Çin & 2936 & 5081 & 9304 & 14455 & 18210 \\
\hline & Hindistan & 2157 & 3039 & 4360 & 6134 & 7762 \\
\hline & Kazakistan & 7919 & 14268 & 19685 & 25123 & 27831 \\
\hline & Kırgızistan & 1651 & 2112 & 2733 & 3453 & 3878 \\
\hline & Pakistan & 2706 & 3433 & 3989 & 4762 & 5544 \\
\hline & Rusya Federasyonu & 6825 & 11822 & 20490 & 24061 & 27147 \\
\hline & Tacikistan & 943 & 1533 & 2095 & 2852 & 3444 \\
\hline & Özbekistan & 2005 & 2743 & 4154 & 6023 & 7020 \\
\hline & ŞİÖ Ortalama & 4055 & 6260 & 9744 & 12661 & 12605 \\
\hline & Türkiye & 9584 & 11888 & 17426 & 25626 & 28816 \\
\hline
\end{tabular}

*Satın alma gücü paritesine göre Milyar Dolar

** Satın alma gücü paritesine göre ABD Doları

Kaynak: Yazarlar tarafından Dünya Bankası veri tabanından elde edilen bilgilere göre hazırlanmıştır.

Sağlık harcamalarının hızla artması hem hane halkı hem de hükümetler için büyük bir endişe haline gelmiştir. Dünya'da ülkelerin sağlığa harcadıkları miktar ve GSYH'dan ayırdıkları pay açısından farklılıklar sözkonusudur (Ke vd., 2011:1). Andersen ve Hussey (2001: 227) kişi başına düşen ortalama gelir seviyesi şeklinde de ifade edilebilen ülkelerin zenginlik seviyelerinin sağlık harcamalarıyla orantılı olduğunu ifade etmiştir. OECD raporunda (2011:1) ekonomik büyümelerin bile üzerinde seyreden GSYH'daki sağlık harcamaları paylarının tüm dünyada yaşanan krizin önemli sebeplerinden birisi olduğunu belirtmiştir. Tablo 3 'te ülkelerin sağlık harcamaları ile ilgili bilgiler yer almaktadır. Toplam sağlık harcamalarının GSYH içindeki payı açısından incelendiğinde; 2000 yılında Özbekistan $(\% 5,36)$, 2005, 2010 ve 2015 y1llarında Kırgızistan (\%7,456,95-7,22) ve 2018 yılında ise Tacikistan'ın (\%7) en yüksek değere sahip olduğu; Pakistan'ın ise yıllar itibariyle \%3'ün altında değerlerle en düşük payı ayırdığı görülmektedir. Türkiye diğer makroekonomik göstergelerde ŞİÖ'ye üye ülkelerle karşılaştırıldığında üst sıralarda yer almasına rağmen GSYH'dan sağlığa ayrılan pay açısından $(\% 4,31-5,05)$ orta sıralarda yer almaktadır.

Tablo 3'deki veriler doğrultusunda kişi başı sağlık harcaması açısından Rusya'nın (367,61-604,03-1089,471328,25-1329,29) y1llar itibariyle en yüksek değerlere sahip olduğu; onu Kazakistan ve Çin'in izlediği görülmektedir. Bununla bilrikte 2000-2005 yıllarında Tacikistan'ın (40,34-79,12;) 2010-2015 ve 2018 y1llarında ise Pakistan'ın $(108,98-134,36-144,12)$ en düşük kişi başı sağlık harcamasına sahip olduğu tespit edilmiştir. Türkiye'nin ŞiÖ’ye üye ülkelerle karşıkaştırıldığında Rusya'dan sonra en yüksek kişi başı sağlı harcamasına sahip olduğu görülmektedir. 
Tablo 3. Ükelerin Sağlık Harcamaları ile İlgili Göstergeler

\begin{tabular}{|c|c|c|c|c|c|c|}
\hline Gösterge & Ülke & 2000 & 2005 & 2010 & 2015 & 2016 \\
\hline \multirow{10}{*}{ 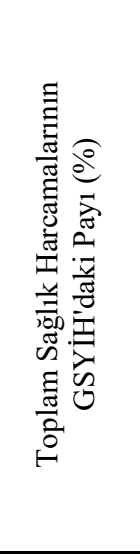 } & Çin & 4,47 & 4,14 & 4,21 & 4,89 & 4,98 \\
\hline & Hindistan & 4,03 & 3,79 & 3,27 & 3,6 & 3,66 \\
\hline & Kazakistan & 4,16 & 3,9 & 2,73 & 3,09 & 3,53 \\
\hline & Kirgizistan & 4,41 & 7,45 & 6,95 & 7,22 & 6,63 \\
\hline & Pakistan & 2,89 & 2,71 & 2,6 & 2,69 & 2,75 \\
\hline & Rusya Federasyonu & 5,01 & 4,76 & 4,96 & 5,28 & 5,27 \\
\hline & Tacikistan & 4,26 & 5,21 & 5,74 & 6,85 & 7 \\
\hline & Özbekistan & 5,36 & 5,04 & 5,35 & 6,1 & 6,34 \\
\hline & ŞİÖ Ortalama & 4,46 & 5,08 & 4,99 & 5,57 & 5,63 \\
\hline & Türkiye & 4,62 & 4,94 & 5,05 & 4,14 & 4,31 \\
\hline \multirow{10}{*}{ 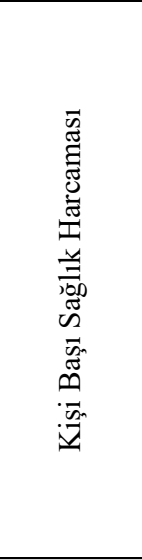 } & Çin & 129,5 & 210,17 & 384,2 & 703,5 & 761,49 \\
\hline & Hindistan & 82,29 & 110,66 & 145,63 & 221,76 & 241,48 \\
\hline & Kazakistan & 324,38 & 541,55 & 534,43 & 764,4 & 858,77 \\
\hline & Kırgizistan & 72,25 & 159,93 & 190,9 & 252,78 & 240,23 \\
\hline & Pakistan & 86,16 & 104,3 & 108,98 & 134,36 & 144,12 \\
\hline & Rusya Federasyonu & 367,61 & 604,03 & 1089,47 & 1328,25 & 1329,29 \\
\hline & Tacikistan & 40,34 & 79,12 & 118,35 & 192,72 & 208,51 \\
\hline & Özbekistan & 105,46 & 135,91 & 218,08 & 373,86 & 416,9 \\
\hline & ŞİÖ Ortalama & 186,82 & 288,45 & 422,57 & 602,59 & 635,87 \\
\hline & Türkiye & 442,89 & 587,45 & 881,5 & 1028,21 & 1089,25 \\
\hline \multirow{10}{*}{ 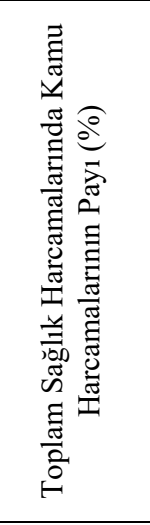 } & Çin & 22 & 32,76 & 51,91 & 60,18 & 58,02 \\
\hline & Hindistan & 20,68 & 20,13 & 26,21 & 25,64 & 25,43 \\
\hline & Kazakistan & 50,94 & 64,58 & 67,62 & 62,03 & 58,79 \\
\hline & Kırgızistan & 48,35 & 50,99 & 49,14 & 37,11 & 39,11 \\
\hline & Pakistan & 35,12 & 21,81 & 22,02 & 27,54 & 27,9 \\
\hline & Rusya Federasyonu & 59,36 & 61,14 & 61,38 & 58,72 & 56,95 \\
\hline & Tacikistan & 20,76 & 18,97 & 20,58 & 28,17 & 28,6 \\
\hline & Özbekistan & 46,96 & 45,16 & 51,08 & 49,83 & 46,13 \\
\hline & ŞİÖ Ortalama & 40,28 & 45,60 & 50,29 & 49,34 & 47,93 \\
\hline & Türkiye & 61,67 & 67,75 & 78 & 78,13 & 78,44 \\
\hline \multirow{10}{*}{ 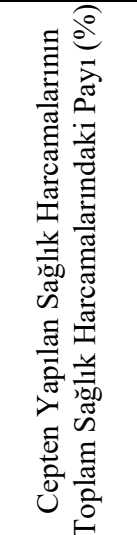 } & Çin & 60,13 & 57,69 & 40,8 & 35,09 & 35,91 \\
\hline & Hindistan & 71,7 & 73,15 & 65,18 & 64,66 & 64,58 \\
\hline & Kazakistan & 48,51 & 34,46 & 27,71 & 31,61 & 35,56 \\
\hline & Kırgızistan & 51,65 & 42,57 & 43,09 & 55,43 & 57,59 \\
\hline & Pakistan & 61,53 & 71,02 & 70,39 & 66,18 & 65,23 \\
\hline & Rusya Federasyonu & 30,21 & 31,93 & 35,33 & 38,65 & 40,48 \\
\hline & Tacikistan & 79,15 & 66,1 & 70,43 & 63,06 & 66,06 \\
\hline & Özbekistan & 52,67 & 49,6 & 46,53 & 48,46 & 52,25 \\
\hline & Şi̇Ö Ortalama & 53,93 & 47,06 & 43,98 & 45,38 & 47,98 \\
\hline & Türkiye & 28,91 & 24,18 & 16,87 & 16,95 & 16,47 \\
\hline
\end{tabular}

Kaynak: Yazarlar tarafından Dünya Bankası veri tabanından elde edilen bilgilere göre hazırlanmıştır. 
Toplam sağlık harcamalarında kamu harcamalarının payı açısından incelendiğinde; 2000 yılında Rusya $(\% 59,36)$ ve takip eden yıllarda ise Kazakistan'ın (\%64,58-67,62-62,03-58,79) en yüksek payı ayırdığı görülmektedir. 2000-2005 ve 2010 yıllarında Tacikistan (\%20,76-18,97-20,58), 2015 ve 2018 yıllarında ise Pakistan'ın $(\% 27,54-27,90)$ ŞiÖ’ye üye ülkeler içerisinde sağlık harcamalarında kamu payının en düşük olduğu anlaşılmaktadır. Türkiye $(\% 61,67-78,44)$ ŞiÖ’ye üye ülkelerle karşılaştırıldığında tüm yıllar itibariyle sağlık harcamalarında kamu payının en yüksek olduğu ülkedir (Tablo 3).

Cepten yapılan sağlık harcamalarının toplam sağlık harcamaları içerisindeki payı açısından incelendiğinde; 2000 yılında Tacikistan $(\% 79,15), 2005$ yılında Hindistan (\%73,15), 2010 yılında Tacikistan $(70,43), 2015$ y1lında Pakistan $(\% 66,18)$ ve 2018 y1lında Tacikistan $(66,06)$ en yüksek orana sahiptir. 2000 ve 2005 yıllarında Rusya (\%30,21-31,93), 2010, 2015 ve 2018 yıllarında ise Kazakistan'ın (\%27,71-31,61-35,56) en düşük cepten yapılan sağlık harcaması oranına sahip oldukları görülmektedir. Türkiye $(\% 28,91-16,47)$ Şı̈Ö'ye üye ülkelerle karşılaştırıldığında tüm yıllar itibariyle cepten yapılan sağlık harcamlaarının toplam sağlık harcamaları içerisindeki payı açısından en düşük olduğu ülkedir (Tablo 3).

Doğumda beklenen yaşam süresi (DBYS), nüfusun genel sağlık durumunu ölçmek ve ülkeler arası karşılaştırmalar yapabilmek için kullanılan en önemli sağlık göstergelerinden biridir ve belirli bir nüfusun belirli bir süre içinde genel mortalite düzeyinin tanımlanabilir ölçüsü olarak ifade edilmektedir (Mahdian, 2016:259; Fok vd., 2012:104; Salomon, 2013:2144).

Tablo 4'te ülkelerin temel sağlı göstergeleri ile ilgili bilgiler yer almaktadır. DBYS yıllar itibariyle tüm ülkelerde artış göstermekle birlikte 2000-2017 yılları arasında DBYS'nin en yüksek olduğu ülkenin Çin (71,9676,41), en düşük olduğu ülkenin ise 2000 yılında Hindistan (62,58), 2005-2017 yılları arasında ise Pakistan $(63,84-66,63)$ olduğu görülmektedir. Kadınlarda DBYS açısından karşılaş̧ııııldığında ise DBYS ile benzer sonuçlar görülmekte; Çin (78) kadınlarda en yüksek DBYS değerlerine sahipken, Pakistan $(67,70)$ en düşük değerlere sahiptir. Erkeklerde DBYS açısından en yüksek değerler DBYS ile benzer şekilde Çin'de(74,95) görülmekteyken; 2000, 2005 ve 2010 yıllarında Rusya (59,03-58,92-63,09), 2015 ve 2018 yıllarında ise Pakistan'da $(65,38-66,63)$ erkeklerde DBYS'nin en düşük olduğu görülmektedir. Türkiye ŞiÖ’ye üye ülkelerle karşılaştırıldığında Çin'den sonra en yüksek; DBYS $(76,01)$, kadınlarda DBYS $(79,22)$, erkeklerde DBYS $(72,76)$ değerlerine sahiptir (Tablo 4).

Bebek ölüm hızı sosyo-ekonomik gelişme ve temel yaşam koşulları gibi genel yapısal faktörlere karşı özellikle duyarlı olması nedeniyle ülkeler arası karşılaştırmalar yaparken kullanılan önemli sağlı göstergelerinden biridir. Bununla bilirkte anne ve yeni doğanların ekonomik ve sosyal durumlarının, kişisel hayat tarzlarının ve dolayısıyla sağlık sistemlerinin seviyesini ve karakteristik özelliklerini de yansıtmaktadır (Reidpath ve Allotey, 2003:344; Daştan ve Çetinkaya, 2015:125). Geçtiğimiz yüzyılda küresel ve bölgesel bebek ölüm hızlarında; HIV salgını nedeniyle bu eğilimde tersine uğrayan Sahra Altı Afrika hariç sürekli bir düşüş yaşanmakla birlikte bu düşüşü korumak ülkeler açısından önemli bir çaba gerektirmektedir (Schell vd., 2007:288). Doğumdan sonraki bir ay içinde ölme olasılığı, neonatal ölüm hızı; doğumdan sonraki bir yıl içinde ölme olasılığı bebek ölüm hızı ve doğumdan sonraki beş yıl içinde ölme olasılığı olarak ifade edilen beş yaş altı ölüm hızı temel bebek ölüm hızlarını ifade etmektedir ve o yıl içerisinde yapılan 1000 canlı doğuma göre hesaplanmaktadır. Tablo 4'te bebek ölüm hızları incelendiğinde; tüm yıllar itibariyle neonatal ölüm hızı, bebek öüm hızı ve beş yaş altı ölüm hızı açısından; Pakistan en yüksek değerleri alırken, Rusya'nın ise en düşük değerlerlere sahip olduğu görülmektedir. 
Tablo 4. Temel Sağlık Göstergeleri

\begin{tabular}{|c|c|c|c|c|c|c|}
\hline Gösterge & Ülke & 2000 & 2005 & 2010 & 2015 & 2017 \\
\hline \multirow{10}{*}{$\begin{array}{l}\mathscr{\nu} \\
\text { 合 }\end{array}$} & Çin & 71,96 & 73,99 & 75,24 & 76,09 & 76,41 \\
\hline & Hindistan & 62,58 & 64,56 & 66,63 & 68,3 & 68,8 \\
\hline & Kazakistan & 65,52 & 65,91 & 68,3 & 72 & 72,95 \\
\hline & Kırgizistan & 68,56 & 67,96 & 69,3 & 70,65 & 71,2 \\
\hline & Pakistan & 62,73 & 63,84 & 65,13 & 66,32 & 66,63 \\
\hline & Rusya Federasyonu & 65,48 & 65,53 & 68,84 & 71,18 & 72,12 \\
\hline & Tacikistan & 65,49 & 67,61 & 69,64 & 70,88 & 71,21 \\
\hline & Özbekistan & 67,15 & 68,37 & 70,01 & 71,19 & 71,42 \\
\hline & ŞİÖ Ortalama & 67,40 & 68,23 & 70,22 & 72,00 & 71,34 \\
\hline & Türkiye & 70,01 & 72,48 & 74,15 & 75,5 & 76,01 \\
\hline \multirow{10}{*}{ 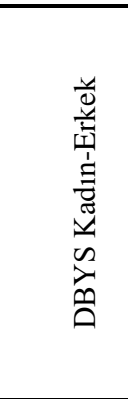 } & Çin & $73,69-70,38$ & $75,57-72,54$ & $76,84-73,77$ & $77,67-74,64$ & $78,00-74,95$ \\
\hline & Hindistan & $63,44-61,79$ & $65,44-63,72$ & $67,84-65,50$ & $69,88-66,86$ & $70,43-67,32$ \\
\hline & Kazakistan & $71,10-60,20$ & $71,80-60,30$ & $73,32-63,51$ & $76,90-67,50$ & $76,92-68,72$ \\
\hline & Kırgızistan & $72,40-64,90$ & $71,90-64,20$ & $73,50-65,30$ & $74,80-66,70$ & $75,40-67,20$ \\
\hline & Pakistan & $63,59-61,97$ & $64,79-62,98$ & $66,09-64,25$ & $67,33-65,38$ & $67,70-65,63$ \\
\hline & Rusya Federasyonu & $72,26-59,03$ & $72,47-58,92$ & $74,88-63,09$ & $76,71-65,92$ & $77,41-67,08$ \\
\hline & Tacikistan & $68,77-62,47$ & $70,77-64,85$ & $72,79-66,96$ & $74,01-68,15$ & $74,36-68,43$ \\
\hline & Özbekistan & $70,41-63,96$ & $71,59-65,23$ & $72,91-67,17$ & $73,95-68,47$ & $74,23-68,65$ \\
\hline & ŞİÖ Ortalama & $71,64-63,40$ & $72,35-64,34$ & $74,04-66,63$ & $75,67-68,56$ & $74,31-68,49$ \\
\hline & Türkiye & $73,79-66,39$ & $75,99-69,07$ & $77,58-70,78$ & $78,74-72,23$ & $79,22-72,76$ \\
\hline \multirow{10}{*}{ 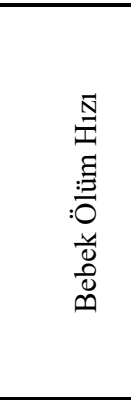 } & Çin & 30,1 & 20,3 & 13,6 & 9,2 & 8 \\
\hline & Hindistan & 66,7 & 55,7 & 45,3 & 35,3 & 32 \\
\hline & Kazakistan & 37,1 & 27,7 & 18,2 & 10,7 & 8,9 \\
\hline & Kırgızistan & 42,2 & 34,3 & 26,1 & 19,8 & 17,9 \\
\hline & Pakistan & 87,9 & 79,8 & 72,8 & 64,6 & 61,2 \\
\hline & Rusya Federasyonu & 16,6 & 11,9 & 8,9 & 7,3 & 6,5 \\
\hline & Tacikistan & 70,5 & 48,5 & 36,9 & 31,3 & 29,4 \\
\hline & Özbekistan & 52 & 41,9 & 31,6 & 22,7 & 20 \\
\hline & ŞİÖ Ortalama & 39,30 & 30,77 & 22,55 & 16,83 & 22,99 \\
\hline & Türkiye & 31,9 & 23,1 & 16,4 & 11,6 & 10 \\
\hline \multirow{10}{*}{ 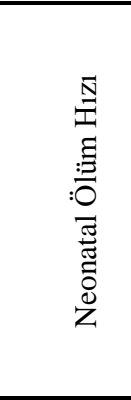 } & Çin & 21,4 & 13,8 & 8,4 & 5,5 & 4,7 \\
\hline & Hindistan & 45,1 & 38,1 & 32 & 26,1 & 24 \\
\hline & Kazakistan & 21 & 15,4 & 10,8 & 5,6 & 5,3 \\
\hline & Kırgizistan & 21,6 & 19,8 & 15,8 & 12 & 10,7 \\
\hline & Pakistan & 60,1 & 53 & 50,6 & 46,3 & 44,2 \\
\hline & Rusya Federasyonu & 9,5 & 6,5 & 4,5 & 3,8 & 3,3 \\
\hline & Tacikistan & 28,4 & 23,3 & 19,8 & 15,7 & 14,5 \\
\hline & Özbekistan & 28,4 & 24,2 & 19,4 & 13,8 & 12,1 \\
\hline & ŞİÖ Ortalama & 20,38 & 17,17 & 13,12 & 9,40 & 14,85 \\
\hline & Türkiye & 19 & 13,7 & 9,2 & 7,1 & 5,9 \\
\hline \multirow{10}{*}{ 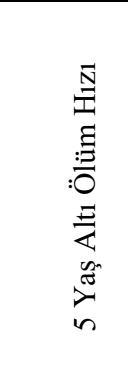 } & Çin & 36,8 & 24 & 15,8 & 10,8 & 9,3 \\
\hline & Hindistan & 91,7 & 74,5 & 58,4 & 44,1 & 39,4 \\
\hline & Kazakistan & 43 & 31,5 & 20,4 & 12 & 10 \\
\hline & Kırgizistan & 49,5 & 39,5 & 29,6 & 22,3 & 20 \\
\hline & Pakistan & 112,6 & 100,9 & 90,8 & 79,5 & 74,9 \\
\hline & Rusya Federasyonu & 19,4 & 13,8 & 10,4 & 8,6 & 7,6 \\
\hline & Tacikistan & 87,6 & 57,7 & 42,8 & 35,8 & 33,6 \\
\hline & Özbekistan & 62,3 & 49 & 36,2 & 25,6 & 22,5 \\
\hline & ŞİÖ Ortalama & 47,26 & 35,92 & 25,87 & 19,18 & 27,16 \\
\hline & Türkiye & 39,2 & 27,5 & 19,2 & 13,4 & 11,6 \\
\hline
\end{tabular}

Kaynak: Yazarlar tarafından Dünya Bankası veri tabanından elde edilen bilgilere göre hazırlanmıştır. 


\section{SONUÇ}

Şanhay Beşlisi olarak 1996'da Çin, Rusya, Kazakistan, Kırgızistan ve Tacikistan'la temeli atılan ve 2011 yılında Özbekistan'ın katılması ile Şanhay İşbirliği Örgütü adını alan yapı, 2017 yılında Hindistan ve Pakistan'ın da katılımı ile hem bölgesel gücünü artırmış hem de küresel anlamda Dünya nüfusunun \%43-44'ünü kapsayacak ölçüde etkili bir konuma gelmiştir.

Ülkelerin gelişmişlik farklılıklarında beşeri sermayenin öneminin vurgulanmasıyla birlikte, sağlık göstergelerinin önemi de artmış ve bu göstergeler gelişmişlik farklarının açıklanmasında sıklıkla kullanılmaya başlanmıştır. Sağlık harcamaları ve bu harcamalardan etkilenen demografik göstergeler, ekonomik gelişmişliğin hem önemli göstergeleri hem de temel belirleyicileri olarak kabul edilmektedir. Bu çalışmada, seçilmiş bazı sağlık harcama ve göstergelerle Türkiye ve ŞïÖ ülkeleri arasında bir karşılaştırma yapılmıştır.

Buna göre, GSYH açısından yapılan karşılaştırmada Şanhay İşbirliği Örgütü’nü oluşturan ülkelerden Çin, Hindistan ve Rusya Federasyonu'nun Türkiye'den daha iyi bir durumda olduğu, ancak kişi başana düşen GSYH bakımından değerlendirildiğinde Türkiye'nin ŞïÖ ülkelerine göre daha iyi durumda olduğu sonucuna ulaşılmıştır. Ayrıca Şiö ülkeleri arasında kişi başı GSYH bakımından en düşük olan Tacikistan, Özbekistan ve Kırgızistan'ın GSYH'dan sağlığa ayırdıkları pay açısından en yüksek ülkeler olduğu görülmektedir. Türkiye'nin GSYH'dan sağlığa ayırdığı pay ise ŞïÖ ülkeleri ortalamasının altında olduğu görülmektedir. Ancak kişi başı sağlık harcamaları açsından değerlendirildiğinde, Türkiye, ŞïÖ ülkeleri içerisinde Rusya Federasyonu'ndan sonra ikinci sırada yer almaktadır. Türkiye kişi başına düşen sağlık harcamaları açısından Şi̇Ö ortalamasının yaklaşık iki katı harcama yaptığı görülmektedir. Yapılan sağlı harcamaları içerisinde kamunun payı Türkiye'de, ŞiÖ ülkelerine göre daha fazla olduğu sonucuna ulaşılmıştır. ŞïÖ ülkelerinde toplam yapılan sağlı harcamalarının yaklaşık yarısı kişilerin cepten yaptığı harcamalar oluşturmaktadır.

İnsani kalkınmanın en önemli göstergelerinden biri yaşam yılı beklentisi olarak kabul edilmektedir. Hem ŞïÖ ülkeleri hem de Türkiye'de yıllar itibariyle doğuştan beklenen yaşam süresinde bir artış trendi görülmektedir. Bebek ölüm hızlarına ilişkin yapılan değerlendirme sonucunda ise, Türkiye, Çin ve Kazakistan'dan sonra en iyi durumda olan üçüncü ülke konumundadır. Yapılan değerlendirmeler sonucunda ülkelerin sağlık harcamalarına ayırdığı oranın artışına paralel olarak sağlık göstergelerinde de olumlu gelişmeler olduğu saptanmıştır.

Sonuç olarak, farklı sağlık sistemlerine, ekonomik ve nüfus yapılarına sahip olan ŞïÖ’ye üye ülkelerle Türkiye karşılaştırıldığında, sağlık harcamaları ve göstergeleri açısından Çin ve Rusya'nın gerisinde, Kırgızistan, Tacikistan ve Özbekistan'ın ise üzerinde olduğu görülmektedir.

\section{KAYNAKLAR}

ANDERSON, Gerard ve HUSSEY, Peter Sotir (2001), "Comparing Health System Performance in OECD Countries", Health Affairs, S.20(3), ss.219-232.

AKÇADAĞ, Emine (2016), “Şanghay İşbirliği Örgütü: Rusya-Çin Ortaklı̆̆ Ml, Rekabeti Mi??, E- Makale, http://www.bilgesam.org/incele/1239/sanghay-isbirligi-orgutu--rusya-cin-ortakligi-mi--rekabeti-mi/\#.V_-A Yx- hqko (Erişim Tarihi: 15.07.2019).

AYDIN, Mustafa, AKGÜL ACIKMESE, Sinem, DIZDAROGLU, Cihan ve KARA, Onur (2018), "Research on Public Perceptions on Turkish Foreign Policy", Center for Turkish Studies - Kadir Has University, 6 June 2018., ss.1-44.

COŞKUN, Orhan (2012), “EU will lose Turkey if it hasn't joined by 2023: Erdogan”, Reuters, 31 October 2012, https://www.reuters.com/article/us-germany-turkey/eu-will-lose-turkey-if-it-hasnt-joined-by-2023erdogan-idUSBRE89 T1TG20121030 (Erişim Tarihi:15.07.2019).

ÇOĞAL, Nejat (2011), “Çok Kutuplu Dünya Projesi: Şangay İşbirliği Örgütü”, E-Makale, http://nejatcogal.com/category/manset/2015/06/09/cok-kutuplu-dunya-projesi-sangay-isbirligi-orgutu/ (Erişim Tarihi:14.07.2019).

EREN, Erdem (2017), “Şanghay İşbirliği Örgütü ve Türk Dış Politikasında Gelecek Perspektifi”, Strategic Public Management Journal, S.3(5), ss.77-94.

EROĞLU, İlhan, UÇGUNOĞLU, Meltem ve KANGAL, Nalan (2016), “Economic Integration Problem of Turkey: An Evaluation about Shanghai Cooperation Organization within the Frame of Alternative Searches", Journal of Economics, Management and Trade, S.13(2), ss.1-18. 
FOK, Marcella Lei-Yee, HAYES, Richard D, CHANG, Chin-Kuo, STEWART, Robert, CALLARD, Felicity J ve MORAN, Paul (2012), "Life Expectancy at Birth and All-Cause Mortality Among People With Personality Disorder”, Journal of Psychosomatic Research, S.73(2), ss.104-107.

GÜPGÜPOĞLU, Emre Rifat (2019), "Shanghai Cooperation Organization and Turkey Relations”, Resolusi: Journal Sosial Politik, S.2(1), ss.45-54.

HAWKSWORTH, John ve COOKSON, Gordon (2006), The World in 2050: Beyond The Brics: A Boarder Look at Amerging Market Growth Prospects, Pricewaterhouse Coopers, Londra.

KARTAL, Burak ve SOFYALIOĞLU, Çiğdem (2011), "Türkiye'deki Gençliğin Şanghay Işbirliği Örgütüne Yönelik Tutumuna Pazarlama Perspektifiyle Bakış", In International Conference On Eurasian Economies, Kyrgyzstan-Turkey Manas University ve Beykent University, 12-14 October 2011 Bishkek, Kyrgyzstan ss.24-29.

KE, Xu, SAKSENA, Priyanka ve HOLLY, Alberto (2011), "The Determinants of Health Expenditure: A Country-Level Panel Data Analysis", Geneva: World Health Organization, Results for Development Institute.

KOZMA, Tamas (2019), "The Shanghai Cooperation Organization on Turkey's Energy Agenda" Asian Journal of Middle Eastern and Islamic Studies, S.13(1), ss.50-64.

MAHDIAN, Mehrdad, SEHAT, Mojbata, FAZEL, Mohammad Reza, RAHIMIAN, Habibollah ve MOHAMMADZADEH, Mandi (2016), "Life Expectancy at Birth in Aran-Bidgol Region, Iran, 2012: A Study Based on Corrected Health Houses Data", International Journal of Epidemiologic Research, S.3(3), ss.259-267.

MENDELSON, Daniel N ve SCHWARTZ, William B. (1993), "The Effects of Aging and Population Growth on Health Care Costs", Health Affairs, S.12(1), ss.119-125.

OECD (2011), "Health: Spending Continues to Outpace Economic Growth in Most OECD Countries", ENews,

https://www.oecd.org/els/healthsystems/healthspendingcontinuestooutpaceeconomicgrowthinmostoecdco untries.htm (Erişim Tarihi: 15.07.2019).

PANTUCCI, Raffaello ve PETERSEN, Alexandros (2013), "Turkey: Abandoning The EU for The SCO", The Diplomat, https://thediplomat.com/2013/02/turkey-abandoning-the-eu-for-the-sco/ (Erişim Tarihi: 15.07.2019).

REIDPATH, Daniel D. ve ALLOTEY, Pascale (2003), "Infant Mortality Rate as an Indicator of Population Health", Journal of Epidemiology \& Community Health, S.57(5), ss.344-346.

SAGBANSUA, Lutfu ve CAN, Nurettin (2011), "Shanghai Cooperation Organization, Turkic Republics and Turkey: Economic and Business Dimensions", Canadian Social Science, S.7(2), ss.80-87.

SALOMON, Joshua A, WANG, Haidong, FREEMAN, Micahel K, VOS, Theo, FLAXMAN, Abraham D, LOPEZ, Alan D. ve MURRAY, Christopher J.L. (2012), "Healthy Life Expectancy for 187 Countries, 1990-2010: A Systematic Analysis for The Global Burden Disease Study 2010", The Lancet, S.380(9859), ss.2144-2162.

SCHELL, Carl Otto, REILLY, Marie, ROSLING, Hans, PETERSON, Stefan ve EKSTROM, Anna Mia (2007), "Socioeconomic Determinants of Infant Mortality: A Worldwide Study of 152 Low, Middle and HighIncome Countries, Scandinavian Journal of Public Health, S.35(3), ss.288-297.

SCO SUMMIT (2019), SCO Summit: PM Modi calls for greater cooperation among members: PTI Bishkek| Updated on June 14, 2019 Published on June 14, 2019, E-Report, https://www.thehindubusinessline.com/news/sco-summit-pm-modi-calls-for-greater-cooperation-amongmembers/article27936882.ece (Erişim Tarihi: 14.07.2019).

T. C. DIŞIŞLERI BAKANLIĞI (2019), Uluslarası Kuruluşlar ve İlişkilerimiz: Şanhay İşbirliği Örgütü (ŞİÖ). http://www.mfa.gov.tr/sanghay-isbirligi-orgutu.tr.mfa (Erişim Tarihi: 15.07.2019).

YENER, M. Cüneyt (2013), "Küresel Düzende Yeni Araylşlar: Şangay İşbirliği Örgütü ve Türkiye”, Uluslararası Ekonomik Sorunlar Dergisi, S.46, ss.71-93. 